\title{
Corticosteroids Can Help Distinguish between Guillain-Barré Syndrome and First Attack of Chronic Inflammatory Demyelinating Neuropathy
}

\author{
An Illustrative Case Report
}

\author{
K. John Alexander Asmahan F. Alshubaili P. Santhamoorthy K.M. Sharafuddin \\ Department of Neurology, Ibn Sina Hospital, Kuwait
}

\author{
Key Words \\ Chronic inflammatory demyelinating polyneuropathy • \\ Corticostereoids · Guillain-Barré syndrome • \\ Immunoglobulins $\cdot$ Plasmapheresis
}

\begin{abstract}
Objective: To report a case of acquired demyelinating neuropathy that failed to improve upon treatment with intravenous immunoglobulins and plasmapheresis but responded dramatically to corticosteroids, illustrating the occasional difficulty in distinguishing Guillain-Barré syndrome (GBS) from a first attack of chronic inflammatory demyelinating polyneuropathy (CIDP). Clinical Presentation and Intervention: A 25-year-old previously healthy man was admitted with a 5-day history of ascending areflexic paralysis of all 4 limbs and diagnosed with GBS. On admission, he was administered intravenous immunoglobulins at a dosage of 400 $\mathrm{mg} / \mathrm{kg} / \mathrm{day}$ for 5 days yet continued to worsen. He became quadriparetic by the second week. As there had been no improvement, he was plasmapheresed with 7 sessions of plasma exchange, $50 \mathrm{ml} / \mathrm{kg}$ of plasma at each session, including appropriate replacement fluid. After failing to improve within 8 weeks, he was started on intravenous methylprednisolone and a dramatic improvement was observed by the 5 th day. He continued to get better on oral prednisolone, was ambulatory with support 4 weeks later and could walk without support on follow-up. Conclusion: This case illustrates that there is a subset of patients initially diagnosed with GBS
\end{abstract}

who do not respond to immunoglobulins or plasmapheresis but do specifically well on steroids. Hence treatment with prednisolone should not be delayed in selective cases of GBS as it may actually be a first episode of CIDP.

Copyright $\odot 2008$ S. Karger AG, Basel

\section{Introduction}

Guillain-Barré syndrome (GBS) is the most common cause of acute flaccid paralysis; the annual incidence in adults in the Middle East is 2.11 per 100,000 population [1]. Immune modulation by intravenous immunoglobulins (IVIG) or plasmapheresis are currently the preferred modalities of treatment of GBS, and both are equally effective [2]. The concurrent administration of IVIG and methylprednisolone showed a marginal benefit after correction for prognostic factors compared to administration of IVIG alone [3]. We report a case of GBS-like symptoms that failed to respond to both IVIG and plasmapheresis but subsequently showed a dramatic improvement with corticosteroids.

\section{Case Report}

A 25-year-old man was admitted complaining of numbness and tingling of the feet as well as rapidly progressing ascending weakness of all 4 limbs for 5 days following a mild upper-respiratory-tract infection. He denied double vision, dysphagia, bladder

\section{KARGER}

Fax +4161306 1234

E-Mail karger@karger.ch

www.karger.com (c) 2008 S. Karger AG, Basel

1011-7571/08/0175-0422\$24.50/0

Accessible online at:

www.karger.com/mpp
Dr. K. John Alexander

Department of Neurology, Ibn Sina Hospital

PO Box 25427

Safat 13115 (Kuwait)

Tel. +965 4840837 ext. 5840, Fax +965 483 5286, E-Mail drkjalex@hotmail.com 
Table 1. Nerve conduction studies of one representative nerve from the right arm and leg

\begin{tabular}{|c|c|c|c|c|c|c|c|}
\hline & & Normal & Admission & 2nd week & 6 th week & 14 th week & 38th week \\
\hline \multirow[t]{11}{*}{ Motor } & Median & & & & & & \\
\hline & CMAP, $\mathrm{mV}$ & $>4.0$ & $18 / 15 / 12$ & $15.7 / 12 / 12$ & $15 / 7.3 / 5.7$ & $12 / 6.3 / 4.6$ & $11 / 4.5 / 4.4$ \\
\hline & $\mathrm{DL}, \mathrm{ms}$ & $<4.0$ & 3.3 & 4.0 & 3.2 & 3.4 & 4.1 \\
\hline & $\mathrm{CV}, \mathrm{m} / \mathrm{s}$ & $>50$ & 48 & 51 & 45 & 38 & 36 \\
\hline & F wave, $\mathrm{ms}$ & $<32$ & 29.4 & 28.8 & 26.9 & 27.4 & 28.2 \\
\hline & Peroneal & & & & & & \\
\hline & CMAP, $\mathrm{mV}$ & $>2.0$ & $4.4 / 1.4 / 1.3$ & $6 / 1.2 / 1.2$ & $2.5 / 0.1 / 0.1$ & $0.27 / 0.1 / 0.1$ & $0.1 / 0.1 / 0.1$ \\
\hline & $\mathrm{DL}, \mathrm{ms}$ & $<5.8$ & 3.6 & 4.5 & 4.4 & 4.2 & 4.3 \\
\hline & $\mathrm{CV}, \mathrm{m} / \mathrm{s}$ & $>40$ & 32 & 31 & 32 & 25 & 27 \\
\hline & F wave, ms & $<58$ & 54.8 & 59.6 & $\mathrm{NE}$ & $\mathrm{NE}$ & $\mathrm{NE}$ \\
\hline & H reflex & $<31$ & $\mathrm{NE}$ & $\mathrm{NE}$ & $\mathrm{NE}$ & $\mathrm{NE}$ & $\mathrm{NE}$ \\
\hline \multirow[t]{3}{*}{ Sensory } & SNAP, $\mu \mathrm{V}$ & & & & & & \\
\hline & Median & $>15$ & 51 & 55 & 46 & 45 & 27 \\
\hline & Sural & $>6$ & 22 & 18 & 18.6 & 17.5 & 6.3 \\
\hline
\end{tabular}

$\mathrm{CMAP}=$ Compound muscle action potential; $\mathrm{DL}=$ distal latency in median nerve at wrist, elbow and axilla; $\mathrm{CV}=\mathrm{conduction}$ velocity in peroneal nerve at ankle, below and above fibula; SNAP = sensory nerve action potential; NE = not elicited.

or bowel disturbances or breathing difficulty. On examination, the patient was a well-built man who was alert, oriented and with normal cranial nerve function. Motor system examination revealed normal bulk of the muscles, albeit with hypotonicity. Medical Research Council Power Scale grades were as follows: upper limbs at the shoulders $4 / 5$; elbows, wrists and fingers $5 / 5$; lower limbs at the hips $1 / 5$; knees $2 / 5$; ankles grade $3 / 5$. Deep tendon reflexes were absent. Sensory examination was normal. He was diagnosed as having GBS, with a score of $4 / 6$ on the Hughes Disability Scale. Nerve conduction study (NCS) revealed a conduction block and decreased conduction velocity that was more evident in the lower limbs, favoring a diagnosis of GBS of the acute inflammatory demyelinating polyneuropathy (AIDP) type. A lumbar puncture showed CSF with no cells, protein $462 \mathrm{mg} / \mathrm{l}$ and glucose $4.6 \mathrm{mmol} / \mathrm{l}$. Routine blood investigations were normal. Screening for collagen vascular diseases, porphyria and toxins was negative. Clinically diagnosed as having GBS, he was started on IVIG at $0.4 \mathrm{mg} / \mathrm{kg} /$ day ( $35 \mathrm{~g}$ daily) on the day of admission and continued on this regimen for 5 days. His condition worsened, with weakness increasing. Two weeks after onset of weakness, the patient had mild bifacial weakness, mild neck muscle weakness and marked weakness (grade 2/5) in all muscle groups of both upper and lower limbs. He was monitored closely for respiratory insufficiency and autonomic instability, neither of which occurred throughout his hospital stay. Serial NCS showed worsening parameters (table 1). Four weeks after the course of immunoglobulins he remained at Hughes grade 4. He was then plasmapheresed with 7 sessions of plasma exchange, $50 \mathrm{ml} / \mathrm{kg}$ of plasma at each session, with appropriate replacement fluid. No improvement was noted and after 8 weeks a repeat lumbar puncture showed WBC at 2 cells $/ \mathrm{mm}^{3}$, protein $243 \mathrm{mg} / \mathrm{l}$ and glucose 3.63 $\mathrm{mmol} / \mathrm{l}$. Eight weeks after weakness onset he was started on intravenous methylprednisolone (500 $\mathrm{mg}$ daily). The response was dramatic, with the patient being able to move his legs by the third

Steroid-Responsive Guillain-Barré

Syndrome day of treatment. After 5 days of intravenous steroids he was switched to oral prednisolone $60 \mathrm{mg} / \mathrm{day}$ and steadily improved thereafter. At the end of 4 weeks of steroids (12 weeks after the onset of illness), he was able to walk with support and had a Hughes grade $3 / 6$. On follow-up 20 weeks after onset he was able to walk without support.

\section{Discussion}

This patient had a rapidly evolving areflexic ascending paralysis with maximum deficit at 2 weeks and features typical of GBS, supported by electrophysiology criteria [4]. The patient failed to respond to IVIG and plasma exchange, both of which are considered standard treatment modalities for GBS. Treatment of GBS with corticosteroids has been abandoned since the landmark study by Hughes et al. [5] and a subsequent multicenter study conclusively proved that there is no therapeutic benefit [6]. Corticosteroids, however, are useful in the treatment of chronic inflammatory demyelinating polyneuropathy (CIDP). In CIDP, the evolution of motor weakness with sensory dysfunction typically occurs over at least 2 months and has a relapsing remitting course, but atypical 'GBS-like presentation' of CIDP has been reported [7]. Mori et al. [8] have described such patients who, after initial improvement with immunoglobulins, relapsed into a chronic phase and subsequently improved only after steroids were initiated [8]. Hughes et al. [9] have described a 
subgroup of steroid-responsive patients who presented with a mild disease evolving over $4-8$ weeks, whom they labeled as 'subacute inflammatory demyelinating polyneuropathy'. Our patient had all the features of GBS and did not respond to IVIG or to plasmapheresis, but instead responded dramatically to corticosteroids, suggesting a diagnosis of CIDP. Hence this patient is illustrative of a group of patients with demyelinating polyneuropathy who present with the clinical and electrophysiological features of GBS yet respond to corticosteroids, but not to the other common immunomodulating therapies. Whether or not our patient has CIDP with a typical relapsing course is not known since he was lost to follow-up. Nevertheless, when it becomes clear that plasmapheresis and/or IVIG are failing, corticosteroids may be initiated earlier in similar cases of GBS because of the possibility of being confronted with an initial episode of CIDP. Se- rial nerve conduction studies have shown that maximum abnormalities occur up to 3 weeks after onset of symptoms in typical cases of GBS and then plateau [10]. However, in this patient nerve conduction abnormalities continued to worsen beyond 3 weeks, even after the motor deficits had peaked. This characteristic may also be a clue for possible CIDP.

\section{Conclusion}

To differentiate atypical cases of CIDP from typical GBS at disease onset is difficult, but corticosteroids should be considered a treatment option because of the potentially dramatic beneficial response, as illustrated by our case.

\section{References}

$>1$ Arami MA, Yazdchi M, Khandaghi R: Epidemiology and characteristics of GuillainBarré syndrome in the northwest of Iran. Ann Saud Med 2006;26:22-27.

$\checkmark 2$ Van der Meche FGA, Schmitz PL: A randomized trial comparing intravenous immunoglobulin and plasma exchange in GuillainBarré syndrome. N Engl J Med 1992;326: 1123-1129.

3 Van Koningsveld R, Schmitz PL, Van der Meche FGA, Visser LH, Meulstee J, Van Doorn PA: Effect of methylprednisolone when added to standard treatment with intravenous immunoglobulins for GuillainBarré syndrome: randomized trial. Lancet 2004;363:192-196.
-4 Asbury AK, Cornblath DR: Assessment of current diagnostic criteria for Guillain-Barré syndrome. Ann Neurol 1990;27(suppl): S21-S24.

$\checkmark 5$ Hughes RAC, Newsom-Davis J, Perkin GD, Pierce JM: Controlled trial of prednisolone in acute polyneuropathy. Lancet 1978;2:750753.

-6 Guillain-Barré Syndrome Steroid Trial Group: Double blind trial of intravenous methylprednisolone in Guillain-Barré syndrome. Lancet 1993;341:586-590.

7 McCombe PA, Pollard JD, McCleod JG: Chronic demyelinating polyradiculoneuropathy. A clinical and electrophysiological study of 92 cases. Brain 1987;110:1617-1630.
$>8$ Mori K, Hattori N, Sugiura M, Koike H, Misu K, Ichimura M, Hirayama M, Sobue G: Chronic inflammatory demyelinating polyneuropathy presenting with features of GBS. Neurology 2002;58:979-982.

$\checkmark$ Hughes R, Sanders E, Hall S, Atkinson P, Colchester A, Payan P: Subacute idiopathic demyelinating polyradiculoneuropathy. Arch Neurol 1992;49:612-616.

10 Albers JW, Donofrio PD, McGonagle TK: Sequential electrodiagnostic abnormalities in acute inflammatory demyelinating polyradiculoneuropathy. Muscle Nerve 1985;8: 528-539. 